\title{
RESEARCH ON TIME-VARYING CHARACTERISTICS OF TESTABILITY INDEX BASED ON RENEWAL PROCESS
}

\section{BADANIE ZMIENNYCH W CZASIE WŁASNOŚCI WSKAŹNIKA TESTOWALNOŚCI NA PODSTAWIE PROCESU ODNOWY}

\begin{abstract}
Testability indices are used in the phases of testability design and testability demonstration. This paper focuses on fault detection rate (FDR), which is the most widely used testability index. Leading hypothesis suggests that the value of FDR of a system is usually a certain value. However, few attempts have been made to research the statistical characteristics of FDR. Considering the fault occurrence process and test uncertainty, FDR is time varying and a special statistical process. Under the assumption of perfect repairs, we build a fault occurrence model based on the renewal process theory. Supposing that test uncertainty is mainly induced by test fault, the renewal process is employed to depict the occurrence process of test faults. Simultaneously, we depict the process of test state change and then construct the fault detection logic based on the digraph model. Combining the fault occurrence model and the fault detection logic, we focus on the expectation of FDR, which is one of the key statistical characteristics. By comparison, we introduce the calculation method of expectation of FDR in two cases, including without considering test uncertainty and considering test uncertainty. To validate the conclusions presented in this paper, we carry on a simulation case using an integrated controller. Based on the theoretic and simulating methods, the expectation of FDR tends to be a constant with the increase of time under the assumptions made in this paper. The statistical characteristic of FDR presented in this paper would be the basic theoretical guide to testability engineering.
\end{abstract}

Keywords: testability index; fault detection rate; renewal process; test uncertainty; statistical characteristics.

\begin{abstract}
Wskaźniki testowalności wykorzystuje się w fazach projektowania oraz potwierdzania testowalności. Przedstawiony artykut poświęcony jest wskaźnikowi wykrywalności blędów (fault detection rate, FDR), który jest najczęściej stosowanym wskaźnikiem testowalności. Wiodąca hipoteza sugeruje, że wartość FDR dla danego systemu jest zwykle wartościa pewną. Istnieje jednak niewiele badań na temat statystycznych własności FDR. Biorąc pod uwagę proces występowania błędów oraz niepewność pomiarów, wspótczynnik FDR można opisać jako zmienny w czasie specjalny proces statystyczny. Przy założeniu naprawy doskonatej, zbudowaliśmy model występowania błędów w oparciu o teorię procesu odnowy. Przyjmując, że niepewność testowa wywoluja głównie błędy testowe, wykorzystaliśmy proces odnowy do zobrazowania procesu występowania błędów testowych. Jednocześnie przedstawiliśmy proces zmiany stanu testu, a następnie zbudowaliśmy logikę wykrywania btędów w oparciu o model grafu skierowanego. Łaczac model występowania btędów z logika wykrywania błędów, opracowaliśmy metodę obliczania wartości oczekiwanej FDR, która jest jedna z najważniejszych wtasności statystycznych tego wskaźnika. Dla porównania, metodę obliczania wartości oczekiwanej FDR zastosowaliśmy w dwóch przypadkach, z uwzględnieniem i bez uwzględnienia niepewności testowej. Aby zweryfikować wnioski przedstawione $w$ niniejszej pracy, przeprowadziliśmy symulację $z$ wykorzystaniem zintegrowanego kontrolera. Obliczenia teoretyczne i symulacja pokazują, że wartość oczekiwana FDR wraz z uptywem czasu staje się wartościa stała $w$ warunkach zalożonych $w$ niniejszej pracy. Przedstawiona $w$ artykule charakterystyka statystyczna FDR stanowi jedna $z$ podstaw teoretycznych inżynierii testowej.
\end{abstract}

Słowa kluczowe: wskaźnik testowalności; wskaźnik wykrywalności błędów; proces odnowy; niepewność testu; wlasność statystyczna

\section{Introduction}

Reliability, maintainability and testability (RMT) have been integral parts of the equipment design. Equipment testability level has effects on operational reliability and maintainability [3], which improves the operational reliability and quick maintenance. For example, shortening mean time to repair (MTTR) needs high requirements of fault detection and isolation capability. After years of theoretical researches and engineering practices, testability index has formed a complete system. It is reported that the number of testability index is as many as dozens[13]. From the point view of clear definition and easy demonstration, these testability indices, such as fault detection rate (FDR), fault isolation rate (FIR) and false alarm rate (FAR) etc., are widely used.

In particular, FDR is one of the most widely used testability index in many engineering practices. FDR is a measure of the capability that faults or failures occurring in the system can be detected by prescriptive test means. Briefly, FDR shows the system ability to indicate the occurred faults. FDR acts as the measure and constraint of the testability level in the design and demonstration phases. In the testability design stage, FDR is the constraint of the product testability level. During this stage, the product purchaser usually proposes a con- 
tract value of FDR. In the testability demonstration stage, the contract value of FDR is the measure to validate product testability level. In this stage, the purchaser would decide whether to accept or reject the product using the statistical sampling method [7, 22, 23]. In order to validate the value of FDR of a series of products, it is assumed that the real value FDR of a test product is a certain number when we use the statistical sampling method [25]. The statistical sampling method is the core theory of the quality inspection. In a quality inspection procedure, the only source of the statistical error is due to random sampling. Currently, the demonstration test of FDR directly employs the theoretical assumptions adopted in the quality inspection. Therefore, if the FDR test based on the quality inspection theory can be used, it must accord to the assumption that the real value of FDR is an existing certain value and do not change. Moreover, the truth is that we pay little attention to the statistical characteristics of FDR. Accordingly, the research on statistical characteristics of FDR is crucial paramount.

FDR is a rate, which reflects the capability of automatic fault indication. Intuitively, the process of fault detection includes two steps. The first step is a fault occurs in a system. The second step, a test means, for example a Built-in Test (BIT), detects the occurred fault and give an indication to the operating or maintenance personnel. Therefore, to achieve the statistical characteristics of FDR, we must have more understandings of the laws of equipment fault occurrence and fault detection.

Modelling of fault occurrence is the key point of reliability and maintainability engineering [21]. The reliability level of a product is its inherent property, which decides the fault occurrence of a product. However, the fault occurrence process also depends on maintenance activities. For example, good maintenance activities can reduce the rate of occurrence of failure (ROCOF) [4]. On the contrary, poor maintenance actions would increase the ROCOF. From the point of view of existing testability engineering, the ROCOF of a product is considered to be constant and the fault interval obeys the exponential distribution [17]. Since the reliability tests carry out separately, testability staff only can obtain product fault information using reliability prediction method. The stochastic process model is related to models of repairable systems in the reliability and maintainability literature $[1,26,28]$. The widely used stochastic process models for repairable systems are the Poisson process, the renewal process (RP), the generalized renewal process (GRP) and the nonhomogeneous Poisson process (NHPP) $[4,11,26]$. The renewal process is commonly used if all the maintenance repairs are preventive maintenance, bringing the system to a "good-as-new" state each time (known as perfect repair). The renewal process (RP) is widely used to depict the fault occurrence process in systems with perfect repairs. The maintenance model was established based on the theory of renewal process and the periodic inspection interval is optimized [21]. Ji et al. [8] introduced to calculate time-varying failure probabilities based on a renewal-processbased model. Kim et al. simulated the failure and repair cycle of a component based on the alternating renewal process[10]. Reference [29] proposed a fault sample simulation approach for virtual testability demonstration test based on the renewal process theory.

The value of FDR is affected not only by the number of fault occurrence but also by the relationships of tests and faults. From a mathematical viewpoint, the dependency matrix (D matrix) can describe the certain relationship among faults and tests[5]. In a dependency matrix, the corresponding element in the $\mathrm{D}$ matrix is one when a test can detect a fault. On the contrary, the matrix element is zero when a fault is undetectable by a test. Considering the actual practice and theoretical study, the relation between a fault and a test is not purely zero or one. This relationship between fault and test is called as the uncertainty relation, also known as the test uncertainty. In this case, the relationship between a test and a fault can be depicted by a decimal between zero to one. Such D matrix is called the uncertainty dependency matrix. Reference [5] focuses on building the diagnostic strategy based on the uncertainty correlation matrix. For the studies of sources of test uncertainty, reference [9] investigates that sensor faults are the main reasons causing the test uncertainty. References [18-20] focus on solving real-time multi-fault diagnosis problem using the theory of imperfect test. The definition of imperfect test is also a way to depict test uncertainty. They define the probability of detection and probability of false alarm to describe the test uncertainty. Accordingly, the relationship between a test and a fault is often uncertain. Generally, the test certainty is only the special case.

FDR is an important indicator of the testability level of a product. As a statistical and time varying parameter, its statistical characteristics are the main points of this paper. This paper proceeds as follow. Section 2 analyses the existing FDR test theory and describes the statistical property of FDR. Section 3 models the fault occurrence process using the renewal process theory. Test uncertainty based on the test fault model is described in Section 4. In Section 5, the expectation of FDR as the key stochastic characteristic is discussed. Section 6 gives a specific simulation example. Conclusions are given in Section 7.

\section{Problem description}

\subsection{Existing test theory of FDR}

The demonstration of FDR is carried out by artificially injecting faults into equipment. Then, the purchaser makes an acceptance/ rejection decision according to the contractual requirement of FDR. The existing demonstration theory of FDR is mainly based on the sampling plan by attributes or sequential probability ratio test $[15$, 24]. The demonstration test of FDR is a Pass/Fail test. It means that each time of the test has two results, including successful detection or failed detection. The basic idea of the demonstration test of FDR is the receiver operating characteristic curve [6]. The characteristic curve $L(p)$ can be written as eq. (1). $L(p)$ is the probability $P\{f \leq c\}$ of an event $f \leq c$. Let $f$ denote the number of failed tests of fault detection. The event $f \leq c$ denotes $f$ is smaller or equal to a specified positive integer $c$ :

$$
L(p)=\sum_{i=0}^{c} C_{n}^{i} p^{n-i}(1-p)^{i}
$$

where $n$ is the number of test samples, $c$ is the maximum number of allowable failed sample and $p$ denotes the probability of success.

Using the sampling plan by attributes or sequential probability ratio test to carry on the FDR demonstration test, we must accept the implicit assumption that the FDR value of a system is a constant depicted as the parameter $p$ in eq. (1). However, researchers have never proved this hypothesis theoretically or using FDR statistical data from the field. In order to validate the availability of this assumption, the statistical model of FDR would be built in next section.

\subsection{Statistical model of FDR}

FDR is defined as a rate, which the number of successfully detected faults is divided by the total number of occurred faults during the specified time interval. According to its definition, FDR is time varying. Here we use the notation $F D R(t)$ to represent fault detection rate at time $t$ and $F D R(t)$ can be calculated as follows [30]:

$$
F D R(t)=\frac{N^{D}(t)}{N(t)}
$$


where $N(t)$ denotes the total occurred number of faults at time $t$ and $N^{D}(t)$ denotes the total number of correctly detected faults at time $t$. Generally, the relationship of $N(t)$ and $N^{D}(t)$ must satisfy $N(t) \geq N^{D}(t)$.
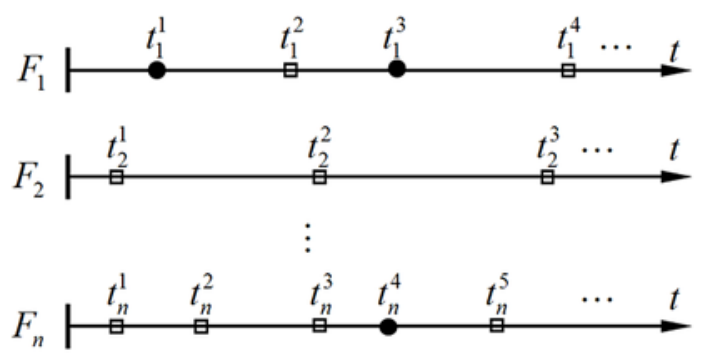

Fig. 1. Counting processes of fault detection in multiple faults system

Let $F=\left\{F_{1}, F_{2}, \ldots, F_{n}\right\}$ denotes a fault set in a system. It means that faults occurred in this system are categorized as $n$ groups. Generally, one of the groups is called a failure mode and we use the term fault to instead. As shown in Fig. 1, each fault $F_{i}$ independently occurs at time $t_{i}^{j}(j=1,2, \ldots)$, where unfilled squares denote successfully detected faults and filled circles denote the undetected faults. Let $N_{F_{i}}(t)$ denote the total occurred number of the fault $F_{i}$ at time interval $[0, t]$. Let $N_{F_{i}}^{D}(t)$ denotes the total number of correctly detected of the fault $F_{i}$ at time interval $[0, t]$. Accordingly, the calculation of $F D R(t)$ can be further rewritten as follows:

$$
\begin{aligned}
F D R(t)= & \frac{\sum_{i=1}^{n} N_{F_{i}}^{D}(t)}{N(t)} \\
= & \frac{N_{F_{1}}^{D}(t)}{N(t)}+\frac{N_{F_{2}}^{D}(t)}{N(t)}+\cdots+\frac{N_{F_{n}}^{D}(t)}{N(t)} \\
& \frac{N_{F_{1}}^{D}(t)}{N_{F_{1}}(t)}+\frac{\frac{N_{F_{2}}^{D}(t)}{N_{F_{2}}(t)}}{N_{(t)}}+\cdots+\frac{\frac{N_{F_{n}}^{D}(t)}{N_{F_{n}}(t)}}{\frac{N_{(}(t)}{N_{F_{n}}(t)}} \\
= & \sum_{i=1}^{n} \lambda_{F_{i}}(t) \cdot r_{F_{i}}(t)
\end{aligned}
$$

where $\lambda_{F_{i}}(t)=N_{F_{1}}(t) / N(t)$ can be defined as an occurring weight, which denotes the proportion of occurred number $N_{F_{1}}(t)$ of the fault $F_{i}$ to $N(t)$. The proportion $r_{F_{i}}(t)=N_{F_{1}}^{D}(t) / N_{F_{1}}(t)$ can be defined as the detection probability of the fault $F_{i}$. The values $\lambda_{F_{i}}(t)$ and $r_{F_{i}}(t)$ lie in an interval $[0,1]$.

From eq. (3), we can clearly find that the value of $F D R(t)$ would be higher if occurring weights of the detectable faults increase. Here, the detectable faults mean that their detection probability $r_{F_{j}}(t)$ is not equal to zero. From the definition of eq. (2), $F D R(t)$ always lies in the interval $[0,1]$. As random variables $N(t)$ and $N^{D}(t)$ are time varying, $F D R(t)$ can be called a statistical process. As shown in Fig. 2, $F D R(t)$ fluctuates between zero to one. The dotted lines are the samples of $F D R(t)$. The heavy line is the expectation $E[F D R(t)]$ of the samples of $F D R(t)$. From the statistical views, we must pour much attention to the statistical characteristics of $F D R(t)$, such as the expectation $E[F D R(t)]$. Therefore, the trend and the statistical characteristics of $F D R(t)$ would be the key points in following sections.

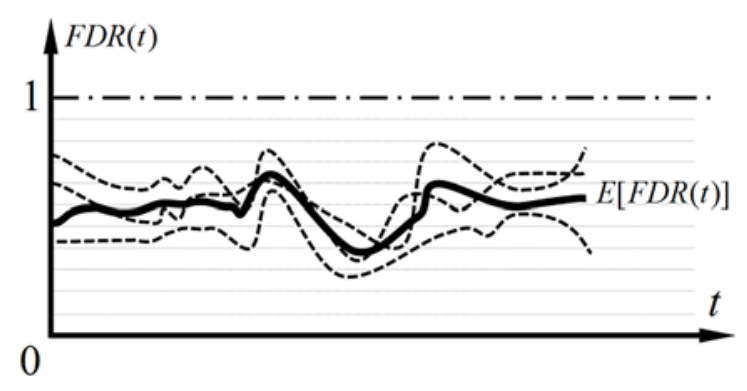

Fig. 2. Time varying characteristic of FDR

\section{Fault occurrence model based on renewal process}

The fault occurrence process is not only affected by its reliability level, but also affected by maintenance activities. Especially for repairable weapons and equipment, they have finite lifetimes that may require corrective maintenance during their lifetimes. During the whole life cycle, their fault occurrence situations should take the effects of maintenance activities into account. According to the effects on fault occurrence from the maintenance activity, maintenance activities can be divided into five categories [26]. Under the assumption of perfect repairs for repairable system, the system is assumed to restore to a 'good-as-new' state each time. Under this maintenance strategy, renewal process is wildly used to depict the fault occurrence processes [27, 28].

In a renewal process, $N(t)$ denotes the number of faults occurred during time interval $[0, t]$. It is a counting process, which has the following properties.

(1) $N(t) \geq 0$.

(2) The value of $N(t)$ is an integer and increases monotonically.

(3) At different times $t$ and $s(s>t)$, the number of occurred fault is denoted as $N(s)-N(t)$ during the interval $[t, s]$. In a counting process, if the value of $N(s)-N(t)$ is only related to the length of the interval $[t, s]$ and has no relation with the starting count time $t$, this counting process is called an independent increment process.

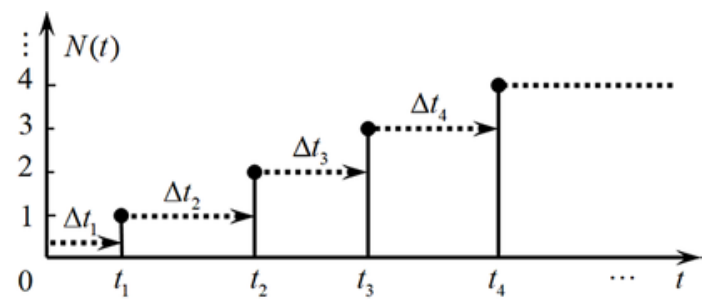

Fig. 3. Counting process of fault occurrence

A sample of counting process of fault occurrence is illustrated in Fig. 3. The fault occurrence times are $\left(t_{1}, t_{2}, t_{3}, \cdots\right)$. We ignore the 
repair time, i.e., the system is repaired and put into new operation immediately after a fault. Let $t_{i}$ denote the occurring time of the $i$ th fault. The interval $\Delta t_{i}=t_{i}-t_{i-1}(i=1,2, \cdots)$ denotes the time interval length between the $(i-1)$ th fault and $i$ th fault. Specially, $t_{0}=0$. We use the term interarrival time to depict the time interval between two successive faults. All of the interarrival times $\left\{\Delta t_{i} \mid i=1,2, \ldots\right\}$ are considered independently and identically distributed. The $n$th fault occurrence time $t_{n}$ can be written as:

$$
t_{n}=\sum_{i=1}^{n} \Delta t_{i}
$$

In the renewal process, the fault interval $\Delta t_{i}$ obeys the same cumulative distribution function $F(t)$ of the interarrival time, namely $\Delta t_{i} \sim F(t)[10]$. Shortly, we define the interarrival time function $F(t)$ to instead. And the probability density function is $f(t)=F^{\prime}(t)$. The $F(t)$ may be the exponential distribution, Weibull distribution, lognormal distribution and Gamma distribution etc. Supposing that $F(t)$ obeys exponential distribution, the renewal process degenerates into a Poisson process. According to the current testability demonstration theory, the assumption that the interarrival time function is an exponential distribution represents that the fault occurrence process is a Poisson process. However, the Poisson process is just a special form of the renewal process[16]. Therefore, it is more universal using the renewal process to describe the process of fault occurrence.

From the mathematical description of the renewal process, it can be described by a function $M(t) . M(t)$ is called the renewal function, which is defined as the expectation of $N(t)$. It can be written as:

$$
\begin{aligned}
M(t) & =E[N(t)] \\
& =\sum_{n=1}^{\infty} n P\{N(t)=n\} \\
& =\sum_{n=1}^{\infty} n\{P\{N(t) \geq n\}-P\{N(t) \geq n+1\}\} \\
& =\sum_{n=1}^{\infty} n\left\{P\left\{t_{n} \leq t\right\}-P\left\{t_{n+1} \leq t\right\}\right\}
\end{aligned}
$$

where $P\{N(t)=n\}$ denotes the probability of $n$ faults in $[0, t]$ and $n=0,1,2, \cdots$.

The random variable $t_{n}$ are the sum of $n$ independent and identically random variables $\Delta t_{i}$, so we can rewrite $M(t)$ as:

$$
\begin{aligned}
M(t) & =\sum_{n=1}^{\infty} n\left\{F^{n}(t)-F^{n+1}(t)\right\} \\
& =\sum_{n=1}^{\infty}\left\{n F^{n}(t)-(n-1) F^{n}(t)\right\} \\
& =F^{1}(t)+\int_{0}^{t} M(t-x) d F(x)
\end{aligned}
$$

where $F^{n}(t)$ denotes the $n$-fold convolution of the time interval distribution function $F(t) \cdot F^{n}(t)$ is the probability that the $n$th fault occurs at time $t$. From the above analysis, $F(t), F^{n}(t)$ and $M(t)$ can determine each other.

For the eq. (6), use the Laplace transform [16]:

$$
M^{*}(s)=F^{*}(s)+M^{*}(s) F^{*}(s)
$$

where $M^{*}(s)$ and $F^{*}(s)$ are the Laplace transform of $M(t)$ and $F(t)$ respectively.

Because $f(t)=F^{\prime}(t)$, so $f(s)=s F(s)$. We can rewrite the eq. (7) as:

$$
M^{*}(s)=\frac{F^{*}(s)}{1-F^{*}(s)}
$$

After obtaining the interarrival time function $F(t)$, the renewal function $M(t)$ can be calculated after the inverse Laplace transform of eq. (8).

\section{Stochastic property modelling of fault detection}

Realistically, the relationship between a fault and a test is uncertain in the actual operation of a system. This section focuses on modelling the test state change and describing fault detection logic.

The results of a test usually have three states, namely correct detection, missed detection and false alarm. The correct detection means that the test indication is consistent with the system occurred fault. The missed detection refers to when there exist a failure, but the test does not give the right fault indication or have no indication at all. A false alarm represents that the test indicates a fault but there is no fault really occurred in a system. References $[19,20]$ define the fault detection probability and the missed detection probability respectively to depict test uncertainty. Considering the definition of $F D R(t)$ according to eq. (2), it only relates to the existed faults whether they can be detected or not. Therefore, the false alarms would not be considered in this paper. So we define a test have two states, including normal state (give right fault indication) and error state (give wrong fault indication or no indication at all). For the sake of simplicity, test states are categorized as $\{0,1\}$, where 1 denotes the normal state and 0 represents the error state.

Reference [2] considered a test appears error state mainly because of sensor failures. Simple to understand, sensor failures mean that a sensor or test circuit itself is in fault. Generally, the reliability level and maintenance strategy of the tests are same as the product itself. Therefore, it is considered that fault occurrence rule of the test is consistent to product itself.

\subsection{Digraph model of fault detection}

In order to carry out the standardized description of fault detection in a system, $F=\left\{F_{1}, F_{2}, \ldots, F_{n}\right\}$ denotes a fault set, which has $n$ independent faults. The independence between faults refers to whether a fault occurs or not does not relate to any other faults in the fault set $F$. In addition, the system has $m$ independent tests, which are grouped as a set $T=\left\{T_{1}, T_{2}, \ldots, T_{m}\right\}$. The independence of a test has two meanings. Firstly, it means that whether the test is in error or normal state keeps independent to other tests. Secondly, a test whether can detect an existing fault is irrelevant to other tests. The relationships among faults and tests can be modelled by a digraph [20]. Fig.4 illustrates a schematic digraph depicting these relationships. In Fig.4, the upper layer nodes represent faults and the lower nodes refer to 


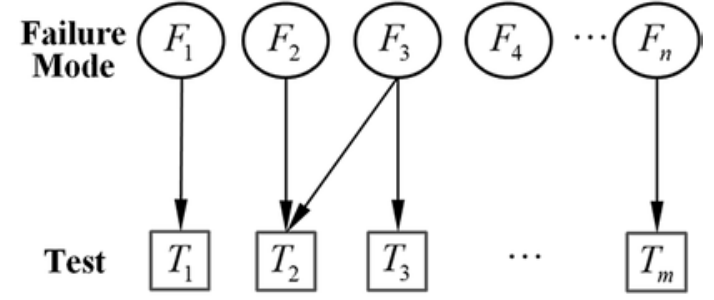

Fig. 4. Digraph of fault detection relationships

tests. In Fig. 4, if there exists the detection relationship between a fault and a test, there is a directed line connection between them.

For notation convenience, we defined the relevant fault set $\operatorname{RFS}\left(T_{j}\right)$ of test $T_{j}$. The set $\operatorname{RFS}\left(T_{j}\right)$ denotes a group of faults can be detected by test $T_{j}$. Mathematically, the set $\operatorname{RFS}\left(T_{j}\right)$ must satisfy:

$$
\operatorname{RFS}\left(T_{j}\right)=\left\{F_{i} \mid F_{i} \in F \text { and } r_{F_{i}}^{T_{j}}=1\right\}
$$

where $r_{F_{i}}^{T_{j}}=1$ denotes that there exists the physical detection relationship between the test $T_{j}$ and the fault $F_{i}$. On the contrary, we define $r_{F_{i}}^{T_{j}}=0$ when the test $T_{j}$ cannot detect the fault $F_{i}$. As shown in Fig. 4, taking the test $T_{2}$ as an example, the relevant fault set of $T_{2}$ is $\operatorname{RFS}\left(T_{2}\right)=\left\{F_{2}, F_{3}\right\}$. Generally, $\operatorname{RFS}\left(T_{j}\right) \neq \varnothing$, where $\varnothing$ denotes an empty set.

Likewise, let $\operatorname{RTS}\left(F_{i}\right)$ denote a relevant test set of the fault $F_{i}$. The $R T S\left(F_{i}\right)$ is a group of tests which can detect the fault $F_{i}$. The set $R T S\left(F_{i}\right)$ must satisfy the condition:

$$
\operatorname{RTS}\left(F_{i}\right)=\left\{T_{j} \mid T_{j} \in T \text { and } r_{F_{i}}^{T_{j}}=1\right\}
$$

As shown in Fig. 4, the relevant test set of $F_{3}$ is $\operatorname{RTS}\left(F_{3}\right)=\left\{T_{2}, T_{3}\right\}$. If a fault $F_{i}$ cannot be detected by any test, it satisfies $\operatorname{RTS}\left(F_{i}\right)=\varnothing$.

\subsection{Modelling of test state change}

The digraph model of between a test and a fault depict the static detection relationship. In this section, we model the test uncertainty based on the assumption of test state change. In reality, the state of a test could not be recognized automatically in the real situation. Generally, when a test does not give right indications to the occurred relevant faults, maintenance staff will affirm that the test is in error state.

It means that the test $T_{i}$ would be repaired and its state switches to be normal only the fault in the set $\operatorname{RFS}\left(T_{i}\right)$ occurs. Otherwise, the test $T_{i}$ will keep its error state. Accordingly, we define a test state change process to depict a test repeatedly change its state from normal to error state then from error to normal state.

To describe the test uncertainty, test fault can be described by the same way as the description of the system fault occurrence. We describe the test fault occurring model using the renewal process. Let $t_{T_{i}}^{j}(j=1,2, \ldots)$ denote the fault time sequence of the test $T_{i}$. It means that the test state change from 1 to 0 at time $t_{T_{i}}^{j}(j=1,2,3, \ldots)$. The fault occurrence law of $T_{i}$ can also described by the renewal function $M_{T_{i}}(t)$. The meaning of $M_{T_{i}}(t)$ is consistent with the definition in Section 3. Simultaneously, let $\tilde{t}_{T_{i}}^{j}(j=1,2,3, \ldots)$ denote the repair time of $T_{i}$. It means that the test state change from 0 to 1 at time $\tilde{t}_{T_{i}}^{j}(j=1,2,3, \ldots)$.

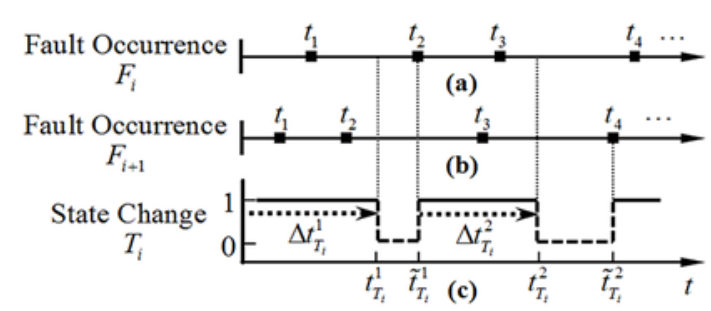

Fig. 5. Schematic diagram of test state change

Fig. 5 illustrates an example of state change process of a test $T_{i}$. The $\operatorname{RFS}\left(T_{i}\right)$ of $T_{i}$ is $\left\{F_{i}, F_{i+1}\right\}$. As shown in Fig. 5, the fault time $t_{T_{i}}^{j}(j=1,2, \ldots)$ of $T_{i}$ is decided by its interarrival time $\Delta t_{T_{i}}^{j}(j=1,1,2, \ldots)$. The repair time $\tilde{t}_{T_{i}}^{j}(j=1,2, \ldots)$ is related to the fault time of the faults in $\operatorname{RFS}\left(T_{i}\right)$. Let $\min \left(t \mid t\left(\operatorname{RFS}\left(T_{i}\right)\right)>t_{T_{i}}^{j}\right)$ denote the minimum time of occurring time of the faults in $\operatorname{RFS}\left(T_{i}\right)$ after the $j$ th fault $t_{T_{i}}^{j}$ of the test $T_{i}$. Consequently, the state change time of $T_{i}$ can be depicted as follows:

$$
\left\{\begin{array}{l}
t_{T_{i}}^{j}=\tilde{t}_{T_{i}}^{j}+\Delta t_{T_{i}}^{j}, j=1,2, \ldots \\
\tilde{t}_{T_{i}}^{k}=\min \left(t \mid t\left(R F S\left(T_{i}\right)\right)>t_{T_{i}}^{j}\right), k=j
\end{array}\right.
$$

Obviously, the fault time $t_{T_{i}}^{j}(j=1,2, \ldots)$ of the test $T_{i}$ would alternates with the repair time $\tilde{t}_{T_{i}}^{j}(j=1,2, \ldots)$, which forms the state change process of $T_{i}$.

\subsection{Description of fault detection logic}

Because of the existence of state change process of a test, the detection probability of the fault $F_{i}$ is less than 1 . The event of fault detection can be modelled as follows.

For a fault $F_{i}$, if it is not detected by any tests, namely $R T S\left(F_{i}\right)=\varnothing, F_{i}$ would not be detected in any case. For a detectable fault $F_{i}$, namely it satisfies $\operatorname{RTS}\left(F_{i}\right) \neq \varnothing$. We define an event $A\left\{F_{i}(t)\right\}$ which represents the detection outcome of $F_{i}$ at the fault occurring time $t$. The event $A\left\{F_{i}(t)\right\}$ has two states $\{s, f\}$. Let $s$ denote that $F_{i}$ is successfully detected and $f$ represents the failed detection. Simultaneously, let $\operatorname{Normal}\left[\operatorname{RTS}\left(F_{i}(t)\right)\right]$ denote the number 
of normal tests in set $R T S\left[F_{i}(t)\right]$ at time $t$. Accordingly, we have the following relationship:

$$
A\left\{F_{i}(t)\right\}=\left\{\operatorname{Normal}\left[R T S\left(F_{i}(t)\right)\right] \geq 1\right\}
$$

where $\quad\left\{\operatorname{Normal}\left(\operatorname{RTS}\left[F_{i}(t)\right]\right) \geq 1\right\}$ denotes the value of $\operatorname{Normal}\left[\operatorname{RTS}\left(F_{i}^{t}\right)\right]$ must be more than or equal to 1 .

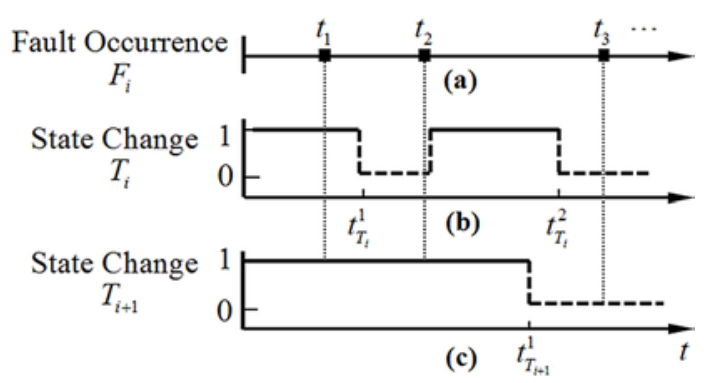

Fig. 6. Schematic diagram of fault detection process

Fig. 6 shows a fault detection process of fault $F_{i}$. Its $\operatorname{RTS}\left(F_{i}\right)$ is the set $\left\{T_{i}, T_{i+1}\right\}$. The fault $F_{i}$ occurs at $\left\{t_{1}, t_{2}, t_{3}\right\}$. According to the fault detection logic depicted in eq. (11), the values of $\operatorname{Normal}\left(\operatorname{RTS}\left[F_{i}(t)\right]\right)$ at $\left(t_{1}, t_{2}, t_{3}\right)$ are 1,2 and 0 respectively. So, results of the event $A\left\{F_{i}(t)\right\}$ at $\left(t_{1}, t_{2}, t_{3}\right)$ are $(s, s, f)$.

\section{Stochastic characteristics of FDR}

In testability test engineering, we usually assume that tests have no uncertainty when the testability tests are carried out under laboratory conditions. It means that if the set $\operatorname{RTS}\left(F_{i}\right)$ is nonempty, the fault $F_{i}$ can be detected at every time when it occurs. For comparison, we divide in two cases to study the stochastic characteristic of $F D R(t)$. In Case 1, we assume that every test keeps normal state all the time. And in Case 2, both the fault occurrence randomness and test uncertainty are considered. In two cases, the final aim is the calculation of the statistical characteristics of $F D R(t)$. In this paper, we mainly focus on the expectation of $F D R(t)$, which is denoted as $E[F D R(t)]$.

\subsection{Case 1}

In this case, we make the following assumptions.

(1) In the fault set $F=\left\{F_{1}, F_{2}, \ldots, F_{n}\right\}$, each fault occurrence process obeys the renewal process;

(2) The tests remain normal all the time. Namely, whether the failure mode $F_{i}$ can be detected is determined. When a fault $F_{i}$ is detectable, its detection probability $r_{F_{i}}$ is equal to one and $F_{i}$ can be detected at any time. Conversely, if a fault $F_{i}$ is undetectable, its detection probability $r_{F_{i}}(t)$ is equal to zero and $F_{i}$ is undetectable at any time.

(3) Every fault $F_{i}$ must obeys the same form of the interarrival time function $F\left(\Delta t ; a_{1}, a_{2}, \cdots\right)$. Only the distribution parameters $a_{1}, a_{2}, \cdots$ are different for different faults.
As the above assumptions, we define the detectable fault set $F^{D}$. The set $F^{D}$ must satisfy

$$
F^{D}=\left\{F_{i} \mid F_{i} \in F \text { and } \operatorname{RTS}\left(F_{i}\right) \neq \varnothing\right\}
$$

Let $\left|F^{D}\right|=k$ represents the number of elements in the set $F^{D}$. According to the above assumption, $r_{F_{i}}(t)$ equals to one or zero. Accordingly, eq. (3) can be further described as:

$$
\begin{aligned}
F D R(t) & =\sum_{i=1}^{n} \lambda_{F_{i}}(t) \cdot r_{F_{i}}(t) \\
& =\sum_{i=1}^{k} \frac{N_{F_{i}}^{D}(t)}{N(t)}
\end{aligned}
$$

where $N_{F_{i}}^{D}(t)$ represents the occurred number of detectable fault $F_{i}$ at time $t$ and $F_{i} \in F^{D}, N(t)$ denotes the occurred number of all faults.

The expectation $E[F D R(t)]$ can be calculated as follows:

$$
\begin{aligned}
E[F D R(t)] & =E\left[\sum_{i=1}^{k} \frac{N_{F_{i}}^{D}(t)}{N(t)}\right] \\
& =\sum_{i=1}^{k} E\left[\frac{N_{F_{i}}^{D}(t)}{N(t)}\right]
\end{aligned}
$$

However, the comprehensive and accurate calculation of eq. (15) is a formidable work. We suppose that the elements in set $F=\left\{F_{1}, F_{2}, \ldots, F_{m}\right\}$ keep independent. Combing eq. (5), the expectation $E[F D R(t)]$ can be approximately calculated as follows:

$$
\begin{aligned}
E[F D R(t)] & =\sum_{i=1}^{k} E\left[\frac{N_{F_{i}}^{D}(t)}{N(t)}\right] \\
& =\sum_{i=1}^{k} \frac{E\left[N_{F_{i}}^{D}(t)\right]}{E[N(t)]} \\
& =\sum_{i=1}^{k} \frac{M_{F_{i}^{D}}(t)}{\sum_{j=1}^{n} M_{F_{j}}(t)}
\end{aligned}
$$

where $M_{F_{i}^{D}}(t)$ refers to the renewal function of the detectable fault $F_{i}^{D} \cdot M_{F_{i}}(t)$ denotes the renewal function of fault $F_{i}$.

From the above analysis, when the form of $F(t)$ changes, $M(t)$ and $E[F D R(t)]$ would have different forms. Based on the above description, the calculation of $M(t)$ is very complicated. Here, taking gamma distribution and exponential distribution for example, the calculation process of $E[F D R(t)]$ is presented.

(1) $F(t)$ obeys gamma distribution

Suppose that the interarrival time function $F(t)$ is a gamma distribution, i.e.: 


$$
F(t)=1-e^{-\lambda t} \sum_{j=0}^{k-1}\left[\frac{(\lambda t)^{j}}{j !}\right] \quad(k=1,2,3 \cdots)
$$

The LS transform of $F(t)$ is as follows:

$$
\begin{aligned}
F^{*}(s) & =\mathrm{L}[F(t)] \\
& =\frac{1}{s}-\frac{1}{s+\lambda} \sum_{j=1}^{k} \frac{\lambda^{k-1}}{s^{k}}
\end{aligned}
$$

Combine with eq. (8):

$$
M^{*}(s)=\frac{\frac{1}{s}-\frac{1}{s+\lambda} \sum_{j=1}^{k} \frac{\lambda^{k-1}}{s^{k}}}{1-\frac{1}{s}+\frac{1}{s+\lambda} \sum_{j=1}^{k} \frac{\lambda^{k-1}}{s^{k}}}=\frac{\lambda^{k}}{(s+\lambda)^{k}-\lambda^{k}}
$$

The inverse LS transform of equation is as follows:

$$
M(t)=\frac{\lambda t}{k}+\frac{1}{k} \sum_{j=1}^{k-1} \frac{\omega_{j}}{1-\omega_{j}}\left[1-e^{-\lambda t\left(1-\omega_{j}\right)}\right]
$$

where $\omega_{j}=e^{2 \pi j i / k}(j=1,2, \ldots, k-1)$ is the distinct root of $s^{k}=1$ and $i$ is an imaginary order

From eq. (20), the limit of $M(t)$ is:

$$
\lim _{t \rightarrow \infty} M(t)=\frac{\lambda t}{k}
$$

According to eq. (21), $M(t)$ can be approximately calculated as:

$$
M(t) \approx \frac{\lambda t}{k}=a t
$$

where $a=\lambda / k$. From eq. (22), $M(t)$ increases linearly with the prolonging of time.

Combine eq. (16) and (22), $E[F D R(t)]$ can be calculated as:

$$
\begin{aligned}
E[F D R(t)] & =\sum_{i=1}^{k} \frac{M_{F_{i}}(t)}{\sum_{j=1}^{m} M_{F_{j}}(t)} \\
& =\sum_{i=1}^{k} \frac{a_{i} t}{\sum_{j=1}^{n} a_{j} t} \\
& =\text { const }
\end{aligned}
$$

where const refers to a constant.

(2) $F(t)$ obeys exponential distribution

When the interarrival time function $F(t)$ is exponentially distributed, namely $F(t)=1-e^{-\lambda t}$. It is a special situation of when $F(t)$ obeys the gamma distribution and $k=1$. In this case, $E[N(t)]=\lambda t=M(t)$.

According to eq. (16), the value of $E[F D R(t)]$ can be calculated as:

$$
\begin{aligned}
E[F D R(t)] & =\sum_{i=1}^{k} \frac{\lambda_{i} t}{\sum_{j=1}^{n} \lambda_{j} t} \\
& =\frac{\sum_{i=1}^{k} \lambda_{i} t}{\sum_{j=1}^{n} \lambda_{j} t} \\
& =\text { const }
\end{aligned}
$$

For the other distribution forms, such as Weibull distribution, it is difficult to obtain the analytical expression of the renewal function $M(t)$. When the time interval $\Delta t$ obeys the interarrival time function $F(t)$, the interarrival time $\Delta t$ can be obtained using Monte Carlo simulation. Accordingly, we can use the Monte Carlo simulation to calculate $M(t)$ and $E[F D R(t)]$.

The core of Monte Carlo method is the process of generating random numbers. The method of generating random numbers includes the inverse distribution generation method and congruence method [12, 14]. Using in the computer simulation, the most widely used method is the inverse distribution method. The procedure is as follows:

Step 1 Calculate the inverse distribution $\Delta t=F^{-1}(U)$ of the interarrival time function $F(\Delta t)=U$.

Step 2 Generate random numbers $u_{1}, u_{2}, \cdots, u_{k}$ which obey a uniform distribution and the values of these numbers must lie between 0 to 1 .

Step 3 Calculating each $u_{i} \in u_{1}, u_{2}, \cdots, u_{k}$ using $\Delta t_{i}=F^{-1}\left(u_{i}\right)$, we can get the interarrival time series $\Delta t_{1}, \Delta t_{2}, \ldots, \Delta t_{k}$.

Under the assumption of certain test, the values of $M(t)$ and $E[F D R(t)]$ are only affected by the number of occurred faults. Fig. 7 illustrates the simulation procedure of a fault occurrence process.

The simulation can be concisely described as follows:

Step 1 For the fault $F_{i}$ and its interarrival time function is $F\left(t \mid F_{i}\right)$.

Generate the fault interval $\Delta t_{F_{i}}^{j}(j=1,2,3, \ldots)$ using the random number generation method.

Step 2 Calculate the fault time $t_{F_{i}}^{i}$ according to $t_{F_{i}}^{j}=t_{F_{i}}^{j-1}+\Delta t_{F_{i}}^{j}$, where $t_{F_{i}}^{0}=0$. When the $t_{F_{i}}^{j}$ reaches the $t_{\max }$, stop the simulation of $F_{i}$. Let $t_{\max }$ denote the maximum time of fault occurrence.

Step 3 Repeat the above two steps and obtain all the time sequences of fault in the set $F=\left\{F_{1}, F_{2}, \ldots, F_{n}\right\}$.

After the above of three steps, we obtain one sample of fault occurrence process. In order to calculate $M(t)$ and $E[F D R(t)]$, we need repeat the simulation procedure. Here, we define the simulation time $S T$. 


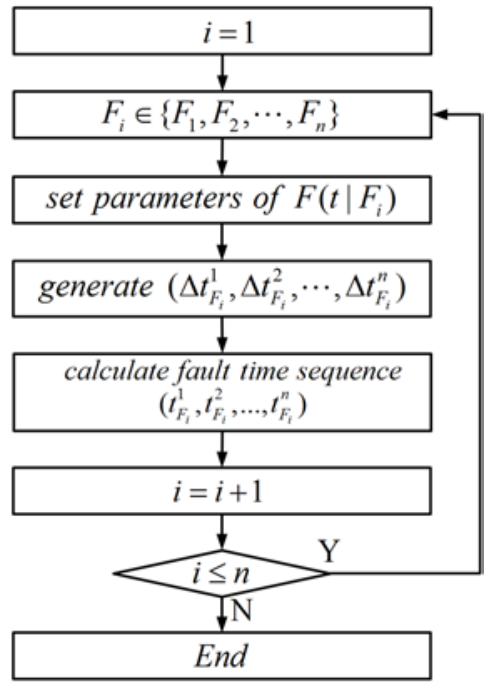

Fig. 7. Simulation flowchart of fault occurrence sequence

(3) $F(t)$ obeys Weibull distribution

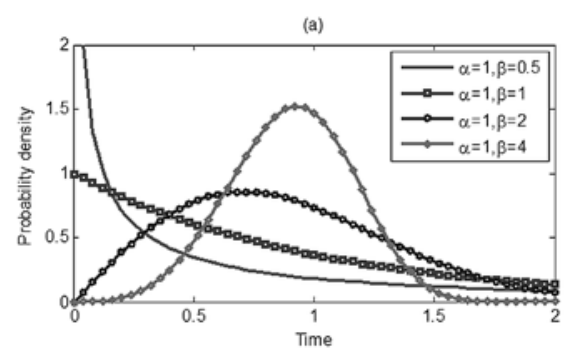

(b)

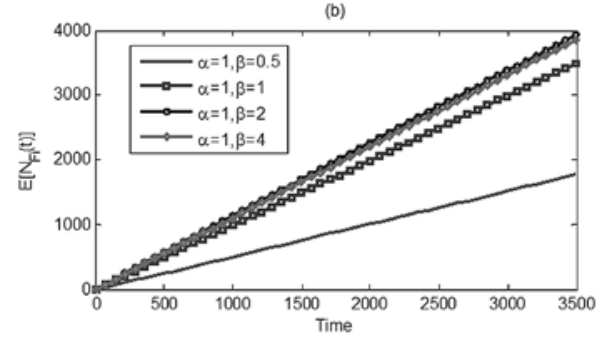

Fig. 8. $E\left[N_{F_{i}}(t)\right]$ under different parameters of Weibull distribution

When the interarrival time function is Weibull distribution, namely $F(t)=1-e^{-(\lambda t)^{\alpha}}$ and $t \geq 0$. Generally, the parameters $\lambda$ and $\alpha$ denote shape parameter and scale parameter respectively. Let $E\left[N_{F_{i}}(t)\right]$ denote the expectation of cumulative number of a fault $F_{i}$ at time $t$. According to the fault occurrence simulation procedure, we simulate the $E\left[N_{F_{i}}(t)\right]$ under four groups of representative distribution parameter as illustrated in Fig. 8. Fig. 8(a) depicts the probability density functions of four different distribution parameters. Fig. 8(b)

illustrates four corresponding curves of $E\left[N_{F_{i}}(t)\right]$. We can clearly find that each $E\left[N_{F_{i}}(t)\right]$ increases linearly and can be approximately expressed as a function $E\left[N_{F_{i}}(t)\right]=a t$, where $a$ is a constant. Similar to the analysis of eq. (23), $E[F D R(t)]$ would tend to be a constant with the increase of time.

According to the theoretical and simulative method proposed in this section, when the fault occurrence process can be modelled by the renewal process and without considering test uncertainty, the value of $E[F D R(t)]$ tends to be a constant.

\subsection{Case 2}

In Case 1, we neglect the test uncertainty. In this case, we would consider the test uncertainty as depicted in Section 4. All for the assumption made in Case 1 are applicable here. In addition, let $T=\left\{T_{1}, T_{2}, \ldots, T_{m}\right\}$ the $m$ independent tests in a system. Every $T_{i}$ in the $T$ will obeys the same interarrival time function $F\left(t ; b_{1}, b_{2}, \cdots, b_{k}\right)$, and only the distribution parameters $b_{1}, b_{2}, \cdots, b_{k}$ are different for different tests.

As shown in eq. (12), the detection condition of the fault $F_{i}$ must satisfy $\operatorname{Normal}\left[\operatorname{RTS}\left(F_{i}(t)\right)\right] \geq 1$. Generally, we define a characteristic function $F D(\cdot)$ which shows whether $F_{i}$ can be detected. At time $t$, the detection state of the fault $F_{i}$ can be written as:

$$
F D\left(F_{i}(t)\right)=\left\{\begin{array}{lc}
1, & \operatorname{Normal}\left[\operatorname{RTS}\left(F_{i}(t)\right)\right] \geq 1 \\
0, & \text { else }
\end{array}\right.
$$

Since we introduce the test uncertainty, the number of detected fault $N_{F_{i}}^{D}(t)$ cannot calculate according to the theory of the renewal process. Therefore, obtaining analytical expression of $E[F D R(t)]$ is a formidable work. So we propose the simulation method to calculate $E[F D R(t)]$.

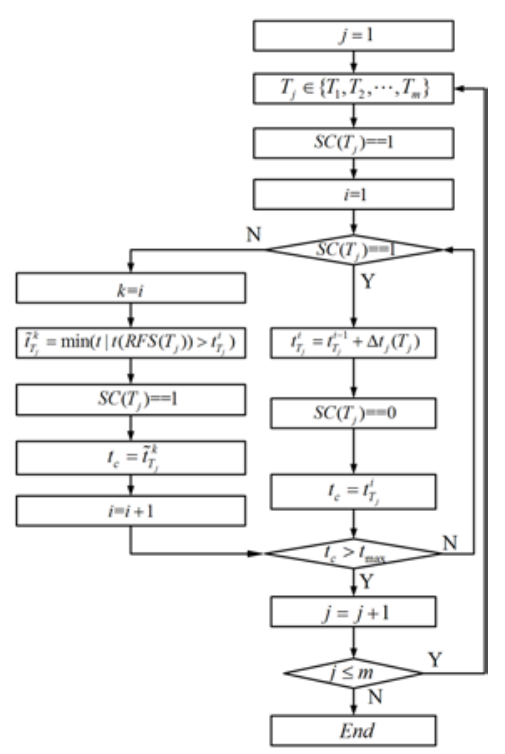

Fig. 9. Simulation flowchart of the process of test state change

To verify the expectation of $F D R(t)$, we must simulate the fault occurrence process and test state change process. In Case 1, we already introduce the simulation procedure of fault occurrence sequence. This section would give the simulation flowchart of test state change process.

First, let $S C\left(T_{j}\right)$ denote the state of test $T_{j}$. When the $T_{j}$ is in normal state, $S C\left(T_{j}\right)==1$. On the contrary, $S C\left(T_{j}\right)=0$ represent $T_{j}$ is in error state. As shown in Fig. 9, it depicts the simulation procedure of the test state change. It can be described as follows. 
Step 1 Set the state change time label $i=1$. From the above description, the length of time $\Delta t_{i}\left(T_{j}\right)$ which a test $T_{j}$ keep normal state is decided by its interarrival time function $F\left(\Delta t_{i} \mid T_{j}\right)$, namely $\Delta t_{i}\left(T_{j}\right) \sim F\left(\Delta t_{i} \mid T_{j}\right)$. When $S C\left(T_{j}\right)==1$, the fault time $t_{T_{j}}^{i}$ of the test $T_{j}$ can be calculated $t_{T_{j}}^{i}=t_{T_{j}}^{i-1}+\Delta t_{j}\left(T_{j}\right)$. Specially, $t_{T_{j}}^{0}=0$. At the time $t_{T_{j}}^{i}$, the $T_{j}$ switches its state from normal to error.

Step 2 When the state of test $T_{j}$ is error, namely $S C\left(T_{j}\right)==0$. As depicted in eq. (11), the repair time is $\tilde{t}_{T_{j}}^{k}=\min \left(t \mid t\left(\operatorname{RFS}\left(T_{j}\right)\right)>t_{T_{j}}^{i}\right) \quad(k=i)$. Then, $i=i+1$.

Step 3 Repeat the above two steps. When $t_{T_{j}}^{i}$ or $\tilde{t}_{T_{j}}^{k}$ reaches $t_{\max }$, stop the simulation of test $T_{j}$.

Step 4 Repeat the above three steps, we would obtain a complete test state change sequence of $T_{j}$. Similarly, we can obtain the other tests' state change sequences.

After the simulation processes of fault occurrence and test state change, the vital step is the statistics the fault detection result. As described above, the fault $F_{i}$ occurs at time $t$, its detection state (determine whether the fault can be detected or not) is decided by eq. (25). So

we can obtain the fault occurrences number $N_{F_{i}}(t)$ and successfully detected times $N_{F_{i}}^{D}(t)$ in the interval $[0, t]$. Likewise, complete the simulation processes of all of the faults in the set $F=\left\{F_{1}, F_{2}, \ldots, F_{n}\right\}$. The total number occurred faults $N(t)$ and detected faults $N^{D}(t)$ can be calculated. Obtaining $N(t)$ and $N^{D}(t)$, we can calculate the $F D R(t)$ according to eq. (2) and obtain a sample curve of $F D R(t)$.

After the entire simulation, we obtain a sample curve of $F D R(t)$. Repeating the above process $S T$ times, we would get $S T$ simulation samples $\left\{F D R^{1}(t), F D R^{2}(t), \ldots, F D R^{S T}(t)\right\}$. Employ the moment estimation method to calculate the expectation $E[F D R(t)]$ as follows:

$$
E[F D R(t)]=\frac{\sum_{i=1}^{S T} F D R^{i}(t)}{S T}
$$

After the whole simulation and calculation procedure, we obtain the $E[F D R(t)]$ and observe its change trend.

\section{Simulation Case}

To verify the theory and simulation method proposed in this paper, an integrated controller in the missile control system is taken as study case. It is used to simulating its fault detection process. Simultaneously, simulating calculation of $E[F D R(t)]$ is carried on.

The integrated controller is a LRU (Line Replaced Unit) level product. Its main functions are outputting the drive and control signals to the four rudders. The test relationship in the integrated controller is shown in Fig. 10.

As illustrated in Table 1, the integrated controller has 11 failure modes $\left\{F_{1}, F_{2}, \ldots, F_{11}\right\}$. The detection method means the way to detect

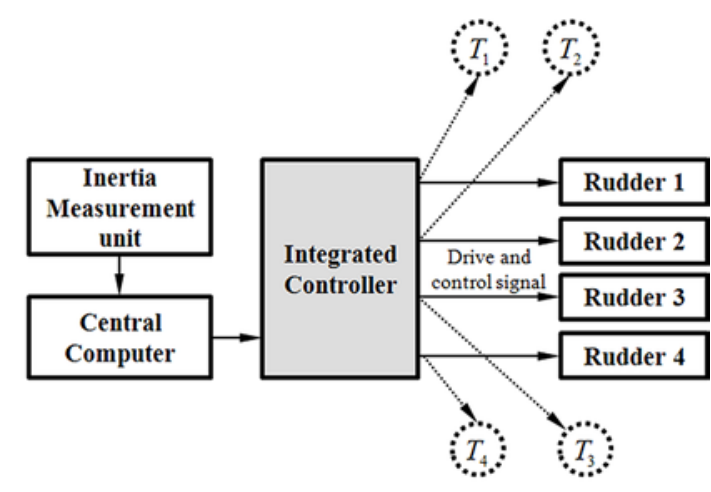

Fig. 10. Test relationship in the integrated controller

a fault, where ATE refers to the automatic test equipment. $T_{i}$ refers to the Built-in Test. The manual test means refers to detect a fault manually. The distribution parameter denotes the parameter of the interarrival time function $F\left(\Delta t \mid F_{i}\right)$, where $F\left(\Delta t \mid F_{i}\right)$ obeys exponential distribution. During the simulation, we only count the fault which can be detected by BIT.

The interarrival time functions of tests $T_{1}, T_{2}, T_{3}, T_{4}$ are exponentially distributed and the parameter of each $F\left(\Delta t \mid T_{i}\right)$ is 1.408 (year).

Table 1. Fault information of the integrated controller

\begin{tabular}{|c|c|c|c||}
\hline Number & Failure Mode & $\begin{array}{c}\text { Detection } \\
\text { Method }\end{array}$ & $\begin{array}{c}\text { Parameter of Interarrival } \\
\text { Time Function (year) }\end{array}$ \\
\hline$F_{1}$ & $\begin{array}{c}1553 \text { B bus com- } \\
\text { munication error }\end{array}$ & ATE & 0.963 \\
\hline$F_{2}$ & $\begin{array}{c}\text { Self-test function } \\
\text { failure }\end{array}$ & Manual test & 0.079 \\
\hline$F_{3}$ & $\begin{array}{c}\text { All the rudder } \\
\text { drive signals error }\end{array}$ & $T_{1}, T_{2}, T_{3}, T_{4}$ & 0.507 \\
\hline$F_{4}$ & $\begin{array}{c}\text { No Rudder 1 drive } \\
\text { signal }\end{array}$ & $T_{1}$ & 0.710 \\
\hline$F_{5}$ & $\begin{array}{c}\text { No Rudder 2 drive } \\
\text { signal }\end{array}$ & $T_{2}$ & 0.710 \\
\hline$F_{6}$ & $\begin{array}{c}\text { No Rudder 3 drive } \\
\text { signal }\end{array}$ & $T_{3}$ & 0.710 \\
\hline$F_{7}$ & $\begin{array}{c}\text { No Rudder 4 drive } \\
\text { signal }\end{array}$ & $T_{4}$ & 0.710 \\
\hline$F_{8}$ & $\begin{array}{c}\text { Error polarity sig- } \\
\text { nal to Rudder 1 }\end{array}$ & $T_{1}$ & 0.152 \\
\hline$F_{9}$ & $\begin{array}{c}\text { Error polarity sig- } \\
\text { nal to Rudder 2 }\end{array}$ & $T_{2}$ & 0.125 \\
\hline$F_{10}$ & $\begin{array}{c}\text { Error polarity sig- } \\
\text { nal to Rudder 3 }\end{array}$ & $T_{3}$ & 0.125 \\
\hline$F_{11}$ & $\begin{array}{c}\text { Error polarity sig- } \\
\text { nal to Rudder 4 }\end{array}$ & $T_{4}$ & 0.125 \\
\hline
\end{tabular}

As shown in Fig. 10, the integrated controller has four independent outputs. In addition, each output is control and drive signal to a special rudder. In the integrated controller, there are four circuits (BIT) to monitor the 4-way signals. These four BITs denotes as $\left\{T_{1}, T_{2}, T_{3}, T_{4}\right\}$ respectively. The test digraph of the integrated controller is built as shown in Fig. 11. The upper nodes $\left\{F_{1}, F_{2}, \ldots, F_{11}\right\}$ refer to faults. The lower nodes $\left\{T_{1}, T_{2}, T_{3}, T_{4}\right\}$ refer to tests. The faults $F_{1}$ and $F_{2}$ cannot be detected by any test in $\left\{T_{1}, T_{2}, T_{3}, T_{4}\right\}$. Specially, the fault $F_{3}$ can be detected by the tests $\left\{T_{1}, T_{2}, T_{3}, T_{4}\right\}$. 


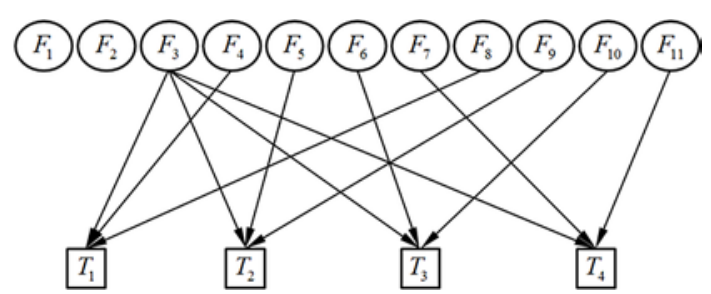

Fig. 11. Test digraph of the integrated controller

In the above discussion, it is divided into two cases to study the statistical characteristics of the $F D R(t)$. However, the simulation of two cases can be carried out together.

Set the simulation time $S T=100$ and the maximum fault time to $t_{\text {max }}=20$ (year) .

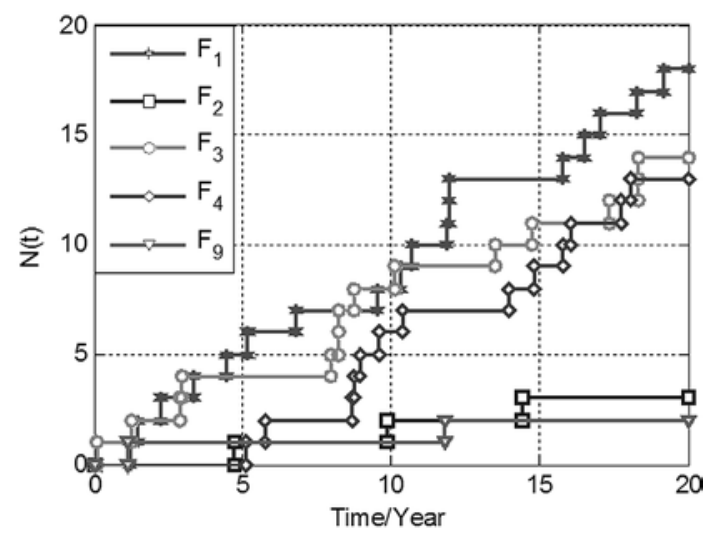

Fig. 12. Example of fault occurrence counting process

Firstly, generate the fault sequence sets of the 11 faults. Fig. 12 shows the fault occurrence counting processes of $\left\{F_{1}, F_{2}, F_{3}, F_{4}, F_{9}\right\}$. For the sake of clarity, it does not illustrate the fault occurrence counting processes of all the 11 faults. Each line in Fig. 11 represents a fault occurrence number $N_{F_{i}}(t)$ of fault $F_{i}$.

Secondly, repeat simulation of fault occurrence 100 times and obtain 100 samples of the fault occurrence processes.

Under the assumption certain test, the detected fault number $N^{D}(t)$ is the sum of the occurred number of faults which can be detected. Here, a fault $F_{i}$ can be detected when it satisfies $\operatorname{RTS}\left(F_{i}\right) \geq 1$. In the integrated controller, faults $F_{3} \sim F_{11}$ are detectable and $\left\{F_{1}, F_{2}\right\}$ are undetectable.

Fig. 13 indicates the expectation of total number of occurred and detected faults, denoted as $E[N(t)]$ and $E\left[N^{D}(t)\right]$ respectively. Both $E[N(t)]$ and $E\left[N^{D}(t)\right]$ approximately linearly increase with the increase of time. $E[F D R(t)]$ can be approximately seemed as the

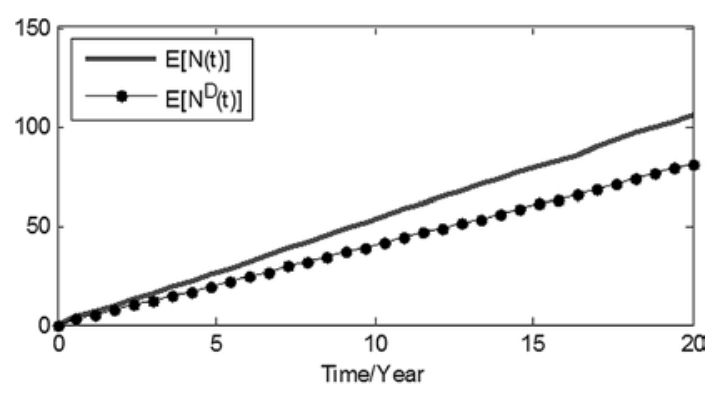

Fig. 13. Expectation of total number of occurred and detected faults

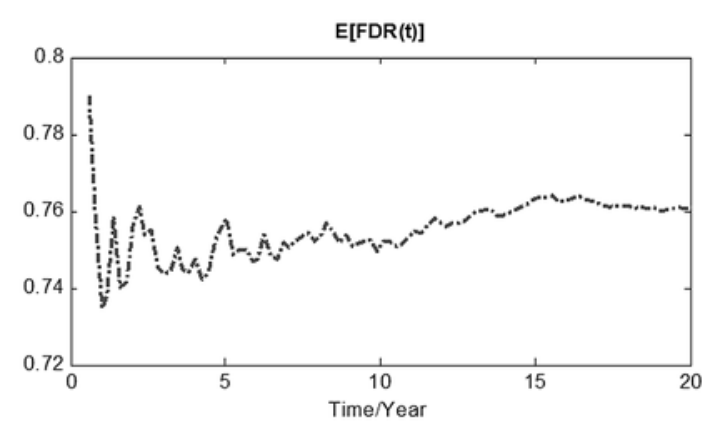

Fig. 14. Time-varying process of $E[F D R(t)]$ under certain test assumption

division of $E\left[N^{D}(t)\right]$ and $E[N(t)]$. Accordingly, $E[F D R(t)]$ might gradually tend to a constant. According to the eq. (26), we can calculate the $E[F D R(t)]$ under the assumption of certain test.

Fig. 14 shows simulation result of $E[F D R(t)]$, where the expectation $E[F D R(t)]$ changes over time and fluctuates acutely at early period then gradually tend to be smoothed and stabilized. Then, we carry on the simulation process based on the assumption of test uncertainty. According to the test state change process and fault detection logic, we obtain four state change sequences of tests $T_{1}, T_{2}, T_{3}, T_{4}$ and fault detection outcomes. As shown in Fig. 15, the state change of test $T_{1}$ is displayed. Simultaneously, the fault occurrence and detection processes of $\operatorname{RFS}\left(T_{1}\right)=\left\{F_{3}, F_{5}, F_{8}\right\}$ are shown. The fault is labelled as a square when it is detected at occurring time. On the other hand, it is labelled as a filled circle when it is not detected at occurring time.

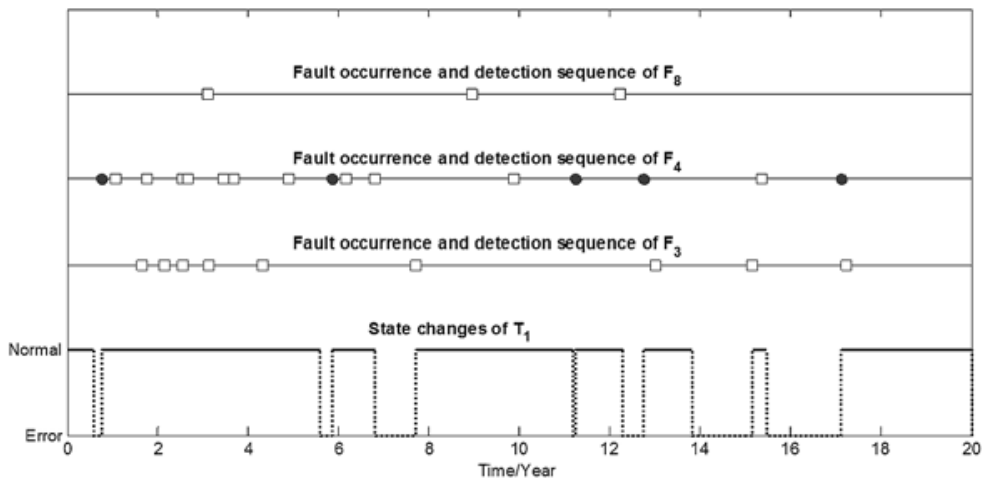

Fig. 15. State change of $T_{1}$ and fault occurrence processes of $\operatorname{RFS}\left(T_{1}\right)$

Next, we count the detected number of faults according to the fault detection logic. By comparison, the expectation values of total number of occurred faults and detected faults in two cases are displayed in Fig. 16. All the three curves have linear increasing charac-

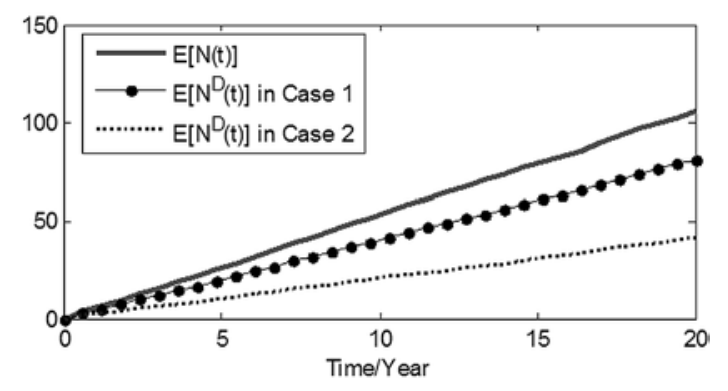

Fig. 16. Expectation of occurred and detected fault number in two cases 


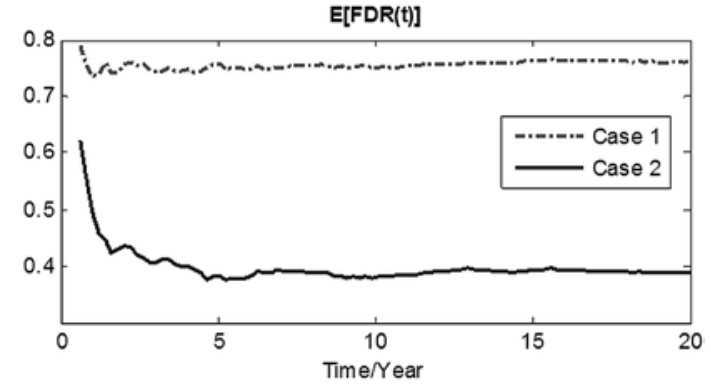

Fig. 17. Time-varying processes of the expectation of FDR(t) in two cases

teristics. Considering test uncertainty in Case 2, the total number of detected faults is less than in Case 1.

In order to compare the $E[F D R(t)]$ in two cases, we display the $E[F D R(t)]$ curves in two cases in Fig. 17. As shown in Fig. 17, two $E[F D R(t)]$ curves have the same law. Both of them fluctuate acutely at the earlier period and gradually get to be stabilised with the increase of time. According to the simulation results in two cases, the FDR real value of the integrated controller could be assumed to be a certain value.

\section{Conclusions}

This paper mainly focuses on the expectation of the statistical process $F D R(t)$, which is one of the most important statistical characteristics. The works of this paper can be concludes as follows.

(1) This paper constructs the fault occurrence model based on renewal process.

(2) This paper presents the test uncertainty model based the reality that test could be in fault and models the test state change process and fault detection logic.

(3) We study the expectation of FDR in two cases, including considering test uncertainty and without considering test uncertainty. In these two cases, the expectations of $F D R(t)$ tend to be a constant along with the increase of time.

(4) When a system obeys laws of fault occurrence and test uncertainty proposed in this paper, we prove the effectiveness of the assumption that the FDR value of a system exists a certain value. Accordingly, the FDR value of this kind of systems could be evaluated by the existing theory of testability demonstration. For systems with other fault occurrence laws, the effectiveness of the assumption needs further studies.

\section{Acknowledgement \\ This research work is supported by National Natural Science Foundation of China (No. 61403408). We would like to thank the editor and the reviewers for their valuable suggestions and comments, which helped to improve our paper.}

\section{References}

1. Attardi L, Pulcini G. A new model for repairable systems with bounded failure intensity. IEEE Transactions on Reliability 2005; 54(4): 572574, http://dx.doi.org/10.1109/TR.2005.858465.

2. Banghart M, Fuller K. Utilizing confidence bounds in failure mode effects analysis (FMEA) hazard risk assessment. IEEE Aerospace Conference 2014: 1-6, http://dx.doi.org/10.1109/AERO.2014.6836222.

3. Barnett N, Bristol. In-service reliability, maintainability and testability demonstrations - 15 years of experience. Annual Reliability and Maintainability Symposium 2003: 587-592, http://dx.doi.org/10.1109/RAMS.2003.118254.

4. Coetzee J L. The role of NHPP models in the practical analysis of maintenance failure data. Reliability Engineering and System Safety 1997; 56(2): 161-168, http://dx.doi.org/10.1016/S0951-8320(97)00010-0.

5. Deng S, Jing B, et al.Yang Z. Test point selection strategy under unreliable test based on heuristic particle swarm optimization algorithm. IEEE Conference on Prognostics and System Health Management (PHM) 2012: 1 - 6, http://dx.doi.org/10.1109/PHM.2012.6228884.

6. Fan S, Pan M, et al.Catherine A. Intercept based performance evaluation of operation characteristic curve. International Conference on Computer Application and System Modeling 2010: V13-173-V13-175, http://dx.doi.org/10.1109/ICCASM.2010.5622707.

7. Feng K. Test-based study on verification model of detection rate in flight test phase. Flight Dynamics 2015; 33(4): 369-370, http://dx.doi. org/10.13645/j.cnki.f.d.20150513.011.

8. Ji G, Wu W, Zhang B, et al. A renewal-process-based component outage model considering the effects of aging and maintenance. International Journal of Electrical Power and Energy Systems 2013; 44(1): 52-59, http://dx.doi.org/10.1016/j.ijepes.2012.07.035.

9. Kacprzynski G J, Goebel K, et al.Vachtsevanos G. Methodologies for uncertainty management in prognostics. IEEE Aerospace Conference 2009: 7-8, http://dx.doi.org/10.1109/AERO.2009.4839668

10. Kim H, Singh C. Reliability modeling and simulation in power systems with aging characteristics. IEEE Transactions on Power Systems 2010; 25(1): 21-27, http://dx.doi.org/10.1109/TPWRS.2009.2030269.

11. Li X, Jia Y, Wang P, et al. Renewable warranty policy for multiple-failure-mode product considering different maintenance options. Eksploatacja i Niezawodnosc - Maintenance and Reliability 2015; 17(4): 551-560, http://dx.doi.org/10.17531/ein.2015.4.10.

12. Liu Q, Zhao P. An analysis method of system mission reliability based on Monte Carlo method. Electronic Product Reliability and Environmental Testing 2013; 31(5): 17-20, http://dx.doi.org/10.3969/j.issn.1672-5468.2013.05.005.

13. Liu Y, Liu J, Jiang P, et al. Selection of equipment testability parameters based on improved AHP and fuzzy evaluation. China Measurement \& Test 2015; 41(7): 23-24, http://dx.doi.org/10.11857/j.issn.1674-5124.2015.07.006.

14. Lu Z, Sun Y. Reliability calculating method of complex systems based on Monte Carlo method and genetic algorithm. Systems Engineering and Electronics 2008; 30(12): 2520-2521, http://dx.doi.org/10.3969/j.issn.1672-5468.2013.05.005.

15. Ma Y, Han J, et al.Li G. Testability demonstration method of electronic equipment based on hypergeometric distribution. IEEE International Conference on Industrial Engineering and Engineering Management 2008 http://dx.doi.org/10.1109/IEEM.2008.4738256.

16. Mitov K V, Omey E, Renewal processes. Springer, 2014, http://dx.doi.org/10.1007/978-3-319-05855-9.

17. Qiu J, Wang C, Liu G, et al. Testability demonstration for a flight control system based on sequential probability ratio test method. Proceedings of the Institution of Mechanical Engineers, Part G: Journal of Aerospace Engineering 2015; 229(3): 492-501, http://dx.doi. org/10.1177/0954410014537239.

18. Ruan S, Yu F, Meirina C, et al. Dynamic multiple fault diagnosis with imperfect tests. Proceedings of AUTOTESTCON 2004: 395 - 401, http://dx.doi.org/10.1109/AUTEST.2004.1436895. 
19. Ruan S, Zhou Y, Yu F, et al. Dynamic multiple-fault diagnosis with imperfect tests. IEEE Transactions on Systems, Man, and CyberneticsPart A: Systems and Humans 2009; 39(6): 1225-1229, http://dx.doi.org/10.1109/TSMCA.2009.2025572.

20. Singh S, Kodali A, Choi K, et al. Dynamic multiple fault diagnosis: mathematical formulations and solution techniques. IEEE Transactions on Systems, Man, and Cybernetics_Part A: Systems and Humans 2009; 39(1): 160-163, http://dx.doi.org/10.1109/TSMCA.2008.2007986.

21. Su C, Zhou X. Maintenance optimization considering dependent competing failure based on renewal process. International Conference on Quality, Reliability, Risk, Maintenance, and Safety Engineering 2013: 620 - 625, http://dx.doi.org/10.1109/QR2MSE.2013.6625657.

22. Wang C, Qiu J, Liu G, et al. Testability demonstration test planning based on sequential posterior odds test method. Proceedings of the Institution of Mechanical Engineers, Part O: Journal of Risk and Reliability 2014; 228(2): 189-199, http://dx.doi.org/10.1177/1748006X13508108.

23. Wang C, Qiu J, Liu G, et al. Testability evaluation using prior information of multiple sources. Chinese Journal of Aeronautics 2014; 27(4): 867-874, http://dx.doi.org/10.1016/j.cja.2014.03.029.

24. Wang C, Qiu J, Liu G, et al. Testability verification based on sequential probability ratio test method. IEEE AUTOTESTCON 2013: 1-7, http://dx.doi.org/10.1109/AUTEST.2013.6645066.

25. Xu P, Liu S, et al.Li Y. Research on concept and model of testability test. China Measurement \& Test 2006; 14(9): 1150-1151, http://dx.doi. org/10.3321/j.issn:1671-4598.2006.09.010.

26. Yanez M, Joglar F, et al.Modarres M. Generalized renewal process for analysis of repairable systems with limited failure experience Reliability Engineering and System Safety 2002; 77(2): 167-180, http://dx.doi.org/10.1016/S0951-8320(02)00044-3.

27. Yang R, Zhao F, Kang J, et al. Inspection optimization model with Imperfect maintenance based on a three-stage failure process. Eksploatacja i Niezawodnosc - Maintenance and Reliability 2015; 17(2): 165-173, http://dx.doi.org/10.17531/ein.2015.2.1.

28. Zantek P F, Hanson T, Damien P, et al. A decision dependent stochastic process model for repairable systems with applications. Operations Research Perspectives 2015(2): 73-80, http://dx.doi.org/10.1016/j.orp.2015.03.002.

29. Zhang Y, Qiu J, Liu G, et al. A fault sample simulation approach for virtual testability demonstration test. Chinese Journal of Aeronautics 2012; 25(4): 598-604, http://dx.doi.org/10.1016/S1000-9361(11)60424-X.

30. Zhang Y, Qiu J, Liu G, et al. Fault sample generation for virtual testability demonstration test subject to minimal maintenance and scheduled replacement. Mathematic Problems in Engineering 2015, http://dx.doi.org/10.1155/2015/645047.

\section{Zhiao ZHAO \\ Jing QIU \\ Guanjun LIU \\ Yong ZHANG}

Science and Technology on Integrated Logistics Support Laboratory, National University of Defense Technology Changsha, Hunan 410073, China

College of Mechatronic Engineering and Automation, National University of Defense Technology Changsha, Hunan 410073, China

E-mails: zza19891013@126.com, qiujing16@sina.com, gjliu342@qq.com, zhangy21cn@126.com 